\title{
Revision total hip replacement with a cemented long femoral component: minimum 9-year follow-up results.
}

\section{$\operatorname{AUTHOR}(S)$ :}

So, Kazutaka; Kuroda, Yutaka; Matsuda, Shuichi; Akiyama, Haruhiko

\section{CITATION:}

So, Kazutaka ... [et al]. Revision total hip replacement with a cemented long femoral component: minimum 9-year follow-up results.. Archives of orthopaedic and trauma surgery 2013, 133(6): 869-874

\section{ISSUE DATE:}

2013-06

URL:

http://hdl.handle.net/2433/189889

\section{RIGHT:}

The final publication is available at Springer via http://dx.doi.org/10.1007/s00402-013 1733-6; This is not the published version. Please cite only the published version.; この論文 は出版社版でありません。引用の際には出版社版をご確認ご利用ください。 


\section{Revision total hip replacement with a cemented long femoral component: Minimum 9-year follow-up results}

Kazutaka So, Yutaka Kuroda, Shuichi Matsuda, and Haruhiko Akiyama

Department of Orthopaedics, Kyoto University, Kyoto, Japan.

Correspondence:

Kazutaka So

Department of Orthopedic Surgery, Kyoto University

54 Kawahara-cho, Shogoin, Sakyo, Kyoto 606-8507, Japan

Tel:81-75-751-3652

Fax:81-75-751-8409

e-mail: so_kazu@kuhp.kyoto-u.ac.jp 


\section{ABSTRACT}

Background. Surgical revision after failed total hip replacement is a technically

challenging procedure. The aim of this study was to analyze the long-term results of revision total hip replacement using a cemented long femoral component and identify factors that influence the results.

Methods. We retrospectively reviewed 34 hips in 33 patients who had undergone revision total hip replacement using a cemented long femoral component between 1994 and 2001. Hip function was evaluated according to the scoring system of the Japanese Orthopaedic Association. Radiographic examination was performed for evaluation of stem loosening, and its possible risk factors were investigated.

Results. The mean follow-up duration was 11.3 years (9-15). Perioperative complications included intraoperative femoral cortex perforation (6 hips, 18\%), dislocation (5 hips, 15\%), deep venous thrombosis (1 hip, 3\%) and postoperative periprosthetic fracture (1 hip, 3\%). The mean preoperative Japanese Orthopaedic Association hip score was $50.3 \pm 14.9$ vs $78.2 \pm 11.5$ at the latest follow-up. The Kaplan-Meier survival rate at 15 years, calculated using radiological failure or re-revision of the femoral component for any reason as the end point, was $87 \%$ or $100 \%$, 
respectively. The failure-free survival rate for the subgroup with a good-quality cement mantle was significantly higher than that for the subgroup with poor quality $(p=0.033)$.

Conclusions. The quality of cementation was identified as a significant risk factor for further loosening. Revision total hip replacement using a cemented long femoral component yielded satisfactory long-term results in this series.

Key words

Total hip arthroplasty, revision, long stem, cement mantle 
1 Revision total hip replacement with a cemented long femoral component: Minimum 9-year follow-up results 2 
3 Background. Surgical revision after failed total hip replacement is a technically challenging procedure. The aim

4 of this study was to analyze the long-term results of revision total hip replacement using a cemented long

5 femoral component and identify factors that influence the results.

6 Methods. We retrospectively reviewed 34 hips in 33 patients who had undergone revision total hip replacement

7 using a cemented long femoral component between 1994 and 2001. Hip function was evaluated according to the

8 scoring system of the Japanese Orthopaedic Association. Radiographic examination was performed for

9 evaluation of stem loosening, and its possible risk factors were investigated.

10 Results. The mean follow-up duration was 11.3 years (9-15). Perioperative complications included 11 intraoperative femoral cortex perforation (6 hips, 18\%), dislocation (5 hips, 15\%), deep venous thrombosis (1

12 hip, 3\%) and postoperative periprosthetic fracture (1 hip, 3\%). The mean preoperative Japanese Orthopaedic

13 Association hip score was $50.3 \pm 14.9$ vs $78.2 \pm 11.5$ at the latest follow-up. The Kaplan-Meier survival rate at

1415 years, calculated using radiological failure or re-revision of the femoral component for any reason as the end 15 point, was $87 \%$ or $100 \%$, respectively. The failure-free survival rate for the subgroup with a good-quality

16 cement mantle was significantly higher than that for the subgroup with poor quality $(p=0.033)$.

17 Conclusions. The quality of cementation was identified as a significant risk factor for further loosening.

18 Revision total hip replacement using a cemented long femoral component yielded satisfactory long-term results

19 in this series.

20

21 Keywords

22 Total hip arthroplasty, revision, long stem, cement mantle 
Surgical revision after failed total hip replacement (THR) is a technically challenging procedure. Although initial attempts were associated with poor results [1], the use of cementless stems in revision THR is now increasing, and good outcomes have been reported both in the short to medium term [2] and in the long term [3]. The stems must be fitted to the femur to obtain initial axial and rotational stability and to enable bone ingrowth into a porous-coated surface or onto an extended coated surface. However, bonding between bone and implant is not easily achieved in the osteoporotic bones of elderly patients or in the case of poor bone stock. Although Malhotra et al. [4] reported that subsidence did not occur in a short term follow-up of hydroxyapatite-coated interlocking stems, subsidence of cementless long stems with a prevalence of $4-8 \%$ in revision THRs was reported in other papers [5-7]. Furthermore, the sclerotic femur with loss of cancellous bone and thinning cortex increases the risk of fracture during surgery. In addition, the use of a distally anchored stem induces stress-shielding, leading to an increased risk of periprosthetic fractures [8], and removal of well-fixed cementless stem is demanding [9]. Concerned about such limitations and complications of revision THR using cementless stems, cemented stems were routinely used at our institute.

High rates of re-revision in cemented revision THR were reported in early publications [10], but cemented revision still has its place in the management of failed THR. There have been reports of good results for cemented femoral revision [11]. Howie et al. [12] investigated 219 revisions of THR in 211 patients using a collarless double-taper cemented femoral component; survival of the long stems to re-revision for aseptic loosening at 9 years was $98 \%$ and for the standard stems it was $93 \%$, results that were better than many cementless designs in terms of survival to aseptic loosening [13]. Cemented stems for revision THR are now generally recommended for the elderly patient with low activity requirements [14].

The aim of this study was to analyze the long-term results of revision THR using a cemented long femoral component. Patient-related and technique-related factors were investigated with respect to radiological and clinical findings.

\section{Patients and methods}

After obtaining institutional board approval, we retrospectively reviewed 114 hips that had undergone cemented revision THR September 1994 and June 2001. Implant infection was screened preoperatively by clinical 
symptoms and the value of C-reactive protein, and diagnosed by cultivation tests of the aspirated joint fluid. Thirteen hips that had undergone revision THR for other than aseptic reasons were excluded from this study. The femoral component was not exchanged in 18 hips, and was exchanged by a standard-length stem in 43 hips. Long femoral components were used in 39 patients (40 hips), who had poor bone stock or intraoperative femoral fracture or perforation. Six patients (6 hips) were lost to follow-up. The remaining 33 patients (34 hips) were reviewed, comprising 4 men and 29 women with a mean age at the time of the revision operation of 64.4 years (range 53-78), a mean height of $151.0 \mathrm{~cm}$ (136-79) and a mean weight of $55.2 \mathrm{~kg}$ (44-72). The mean follow-up duration was 11.3 years (9-15).

The initial diagnoses at the time of the initial THR were osteoarthritis secondary to acetabular dysplasia in 20 hips, trauma in 4, osteonecrosis of the femoral head in 2, tuberculous arthritis in 1 and unknown in 7. Previous operations included 28 THRs and 6 bipolar hemiarthroplasties, with Charnley stem (Depuy, Leeds, UK) in 22 hips, Bioceram stem (Japan Medical Materials, Osaka, Japan) in 5, Physio-hip System KC stem (Japan Medical Materials) in 1, Physio-hip System Type 6 stem (Japan Medical Materials ) in 1, Harris precoated stem (Zimmer, Warsaw, Indiana ) in 1, Hasting hip stem (Depuy) in 1, Mizuhoika COP stem (Mizuhoika, Tokyo, Japan) in 1, Moore stem in 1 and unknown in 1. The mean time from the primary THR to the revision was 11.5 years $(2-20)$.

Operations were performed using an anterolateral approach as described by Dall, Hardinge or Lindgren [15-17]. The acetabular components in 31 hips were replaced because they were loose or worn. After the old femoral component had been removed, thorough debridement of the cement and fibrous tissue was undertaken using a chisel, curette, high-speed burr and reamer. Allogenic bulk bone from the resected femoral heads was grafted onto the segmental bone defect in 10 hips. Allogeneic morselized cancellous bone was grafted in 13 hips to fill the cavitary defects caused by reverse reaming, which was reported originally for acetabular bone grafts $[18,19]$. The long femoral components included HS-3 (Japan Medical Materials) in 17 hips, Physio-hip System Type 6 (Japan Medical Materials) in 14, Physio-hip System Type 7 (Japan Medical Materials) in 1 and Elite Plus (Depuy) in 2 (Figure 1). Stems of the HS-3 and Elite Plus are cylindrical, and those of the Type 6 and Type 7 are rectangular column. The mean stem length was $176 \mathrm{~mm}$ (140-250). CMW3 cement (Depuy) or Endurance cement (Depuy) was used until 1999 or since 2000 for implant fixation, respectively. The cementing was performed using a third-generation technique: distal plugging, lavage and retrograde insertion of vacuum-mixed cement with a cement gun. Antibiotics were administered intravenously 30 min before surgery, and at 6 and $18 \mathrm{~h}$ 
81

82

postoperatively. Mobilization involved one-third partial weight bearing between parallel bars or with a walking frame usually starting 2 weeks after surgery, with the patient progressing to full weight bearing over the next 4 weeks.

An anteroposterior radiograph of the hip was made preoperatively and at each follow-up examination. Femoral bone defects were evaluated on the basis of preoperative radiographs, according to the classification of Paprosky [20]: Type I in 2 hips, Type II in 2, Type IIIa in 16, Type IIIb in 6 and Type IV in 8 . The mantle of cement in the femur was graded on the basis of postoperative radiographs, according to the criteria of Barrack [21]. Radiological loosening of the stem was evaluated by comparing the postoperative radiographs with those taken at each follow-up, as described by Harris [22].

Hip function was evaluated according to the scoring system of the Japanese Orthopaedic Association (JOA) before the revision operation and at the latest follow-up.

\section{Statistical analysis}

The Wilcoxon signed-ranks test was used for evaluation of the JOA score. The Kaplan-Meier method with 95\% confidence intervals (CIs) was used to estimate the cumulative probabilities of stem re-revision and radiological failure (re-revision and definite and probable loosening). The log-rank test was used to evaluate the possible risk factors for radiological stem failure. The possible risk factors included age, body mass index (BMI), grade of femoral bone defect, intraoperative perforation of the femoral cortex, bone graft, type of new stem (cylindrical or rectangular) and the grade of cement mantle. For evaluating age and BMI, the cases were divided into 2 groups based on their mean values. For evaluating bone defects, comparison among cases with each Paprosky Type, and between cases with Paprosky Type I or II and those with Type IIIa, IIIb or IV defects were performed. Statistical significance was assumed at $\mathrm{p}<0.05$.

Institutional review board approval was obtained for publication of the study. The patients and their family were informed that data from the cases would be submitted for publication and gave their consent.

\section{Results}

The mean operating time was 227 minutes (range 120-323) and the mean intraoperative blood loss was $908 \mathrm{ml}$ (140-2020). The JOA hip scores increased from a mean preoperative value of 50.3 (24-79) to a mean of 78.2 
110 (58-98) postoperatively ( $<$ 0.01): $19.7(0-35)$ to $37.8(35-40)$ in pain $(\mathrm{p}<0.01), 13.0(6-18)$ to 13.4 (6-18) in

111 mobility ( $\mathrm{p}=0.2), 7.7(0-15)$ to $10.4(5-20)$ in walking $(\mathrm{p}<0.01)$ and $11.2(2-16)$ to $14.9(6-20)$ in physical

112 activity $(\mathrm{p}<0.01)$. Intraoperative complications occurred in 6 hips with perforation of the femoral cortex.

113 Postoperative complications occurred in 6 hips, comprising dislocation in 4, dislocation and deep venous

114 thrombosis in 1 and periprosthetic fracture in 1 at 1 year after operation. Two hips required further revision of the acetabular component for recurrent dislocation.

116

The radiological outcomes were assessed from the initial and the follow-up radiographs. The increase in stem length corresponded to a mean of $3.6 \pm 2.8$ femoral canal diameters. The quality of the cement mantle in the initial postoperative radiograph was graded as A in 7 hips, B in 20, C in 7 and D in none. The stem was not loose in 29 hips, possibly loose in 3, probably loose in 1 and definitely loose in 1 at the final follow-up. The radiolucent lines usually appeared proximally and progressed distally (Figure 2). At the final follow-up, radiolucent lines were most frequent in Gruen zones 1 (74\%) and 7 (65\%) (Table 1). Focal periprosthetic osteolysis was observed in 4 hips. Varus-valgus alignment did not change during the observation period. The definitely loosened stem showed a subsidence of $0.5 \mathrm{~mm}$ at the final follow-up. any reason as the end point. The survival rate was $87 \%$ at 15 years (95\% CI 73-100) using radiological failure of the femoral component as the end point. Among 27 hips with a good-quality cement mantle (Barrack grades A or B), no hip resulted in radiological failure of the femoral component, whereas 2 of 7 hips with poor quality (Barrack grade C) resulted in radiological failure. The rate of survival was $100 \%$ at 15 years in hips with Barrack grades A or B and 64\% (95\% CI 23-100) at 13 years in hips with Barrack grade C using radiological failure of the femoral component for any reason as the end point (Figure 3). The failure-free survival rate for the subgroup with a good-quality cement mantle was significantly higher than that for the subgroup with poor quality (log-rank test $\mathrm{p}=0.033$ ). Type of femoral bone defect did not significantly affect the survival rate (log-rank test $\mathrm{p}=0.84)$. Another comparison between hips with Type I or II defects (100\% at 15 years) and those with Type IIIa, IIIb or IV defects (84\% at 15 years) also did not reveal significant difference $(\mathrm{p}=0.54)$. Age $(p=0.18)$, BMI $(p=0.61)$, perforation of the femoral cortex $(p=0.49)$, bone graft $(p=0.088)$ and type of revision stem $(\mathrm{p}=0.63)$ did not significantly affect the failure-free survival rate of the stem.

137

\section{Discussion}


139 Many operative procedures for revision of failed THR, including the use of cemented long implants [23], the

140 use of cementless implants [2, 3] and different bone grafting techniques [24, 25], have been introduced, but the

141 optimal approach has yet to be defined. Cemented revision still has a place in the management of patients with a failed THR with various clinical outcomes, and these previous studies have reported risk factors for recurrent loosening of the femoral component after cemented revision.

The loss of the proximal femur and endosteal cancellous bone and the presence of a thin sclerotic cortical bone at femoral diaphysis at revision surgery substantially reduce the stability of the revision stem. To obtain distal fixation at the cement-bone interface for initial implant stability, some studies showed better outcomes for a longer revision stem that extends beyond the primary stem [11, 23]. Retpen and Jensen [26] reported an increased risk of stem loosening when the revision stem overbridged the tip of the primary stem by less than one diameter of the femoral shaft. Experimental studies by Mann et al. [27] showed that the femoral component should extend beyond the area of cancellous bone defect by at least 2 femoral diameters to minimize the risk of loosening. In the present study, the mean increase in the stem length amounted to 3.6 femoral canal diameters greater than the primary stems and the Kaplan-Meier survival rate at 15 years, calculated using radiological failure or re-revision of the femoral component for any reason as the end point, was $87 \%$-similar to the outcomes reported by other groups [12, 28]. In addition, Callaghan et al. [29] found that when a long stem was used, progression of radiolucent lines was less likely to occur. Therefore, although Strömberg and Herberts [30] reported no relationship between improvement of femoral fixation and the use of longer revision stems, we believe that a long stem in revision THR is a better choice to obtain stem stability by bypassing all areas of osteolysis or cortical thinning. Previous studies showed that revision THR using first-generation cementing techniques was discouraging. Kavanagh et al. [31] reported a radiological probable loosening rate of $44 \%$ at a mean of 4.5 years of follow-up. The Swedish Hip Registry also revealed that improved cementing techniques had a significant effect on revision rates [32]. In contrast, the radiological and clinical results of the revised femoral stem have improved since the introduction of second- and third-generation cementing techniques [11, 30]. For a sclerotic femur with loss of cancellous bone during loosening and subsequent revision surgery, it is obviously difficult to obtain interdigitation between cement and bone. Furthermore, cortical thinning causes microseparations between cement and bone. Dohmae et al. [33] showed that interface shear strength was reduced to 20.6\% of primary strength at the first revision surgery and to $6.8 \%$ at the second. Therefore, better distribution of the 
168 cement into the femoral canal and retention of cement-bone bonding by modern cementing techniques are

169

170

171

172

173

174

175

176

177

178

179

180

181

182

183

184

185

186

187

188

189 prerequisites for long-term mechanical stability of the revised stem. Our result that the rate of survival in hips with Barrack grades A or B was much better than that in hips with Barrack grade C supports this conclusion.

The present study reports good results in a relatively elderly patient group (mean age 64.4 years). Previous studies $[11,26]$ reported younger age or increased activity as a major risk factor for recurrent aseptic loosening. The frequency of mechanical failures tends to increase in younger and more active patients. In contrast, Pierson and Harris [34] reported excellent results for 66 hips in young patients using second-generation cementing techniques. The discrepancies among these results might be related to operative procedures, femoral implants or the degree of femoral bone loss.

There are some limitations in this study. First, the study population was relatively small. In addition, follow-up rate was relatively low. Six out of 39 patients were lost to follow-up within 9 years postoperatively. Second, lateral radiographs and computed tomography images of the hip were not investigated in this study. Mall et al. [35] reported that only 54\% of patients with lysis seen on computed tomography examination had radiographic evidence of osteolysis. Evaluation of the radiolucent line, osteolysis and stem loosening may have not been sufficient.

Revision total hip replacement using a cemented long femoral component yielded satisfactory long-term results in this series. This technique can be recommended even in cases with large bone defect, but should be performed with care to obtain a good-quality cement mantle.

The authors did not receive any outside funding or grants in support of their research for or preparation of this work. 
191 1. Hedley AK, Gruen TA, Ruoff DP (1988) Revision of failed total hip arthroplasties with uncemented 192 porous-coated anatomic components. Clin Orthop Relat Res 235:75-90

193 2. Böhm P, Bischel O (2001) Femoral revision with the Wagner SL revision stem: evaluation of one 194 hundred and twenty-nine revisions followed for a mean of 4.8 years. J Bone Joint Surg Am 83:1023195 1031

196 3. Raman R, Kamath RP, Parikh A, Angus PD (2005) Revision of cemented hip arthroplasty using a hydroxyapatite-ceramic-coated femoral component. J Bone Joint Surg Br 87:1061-1067

4. Malhotra R, Dua A, Kiran EK, Bhan S (2007) Femoral revision using long hydroxyapatite-coated interlocking stem. Arch Orthop Trauma Surg 128:355-362

5. $\quad$ Fink B, Grossmann A, Schubring S, Schulz MS, Fuerst M (2009) Short-term results of hip revisions with a curved cementless modular stem in association with the surgical approach. Arch Orthop Trauma Surg 129:65-73

6. Mertl P, Philippot R, Rosset P, Migaud H, Tabutin J, Van de Velde D (2011) Distal locking stem for revision femoral loosening and peri-prosthetic fractures. Int Orthop 35:275-282

7. Neumann D, Thaler C, Dorn U (2012) Management of Vancouver B2 and B3 femoral periprosthetic fractures using a modular cementless stem without allografting. Int Orthop 36:1045-1050

8. Yamada H, Yoshihara Y, Henmi O, Morita M, Shiromoto Y, Kawano T, Kanaji A, Ando K, Nakagawa M, Kosaki N, Fukaya E (2009) Cementless total hip replacement: past, present, and future. J Orthop Sci $14: 228-241$

9. Schmidt J, Porsch M, Sulk C, Hillekamp J, Schneider T (2002) Removal of well-fixed or porous-coated cementless stems in total hip revision arthroplasty. Arch Orthop Trauma Surg 122:48-50

10. Eisler T, Svensson O, Iyer V, Wejkner B, Schmalholz A, Larsson H, Elmstedt E (2000) Revision total hip arthroplasty using third-generation cementing technique. J Arthroplasty 15:974-981

11. Hultmark P, Kärrholm J, Strömberg C, Herberts P, Möse CH, Malchau H (2000) Cemented first-time revisions of the femoral component: prospective 7 to 13 years' follow-up using second-generation and third-generation technique. J Arthroplasty 15:551-561 
217 12. Howie DW, Wimhurst JA, McGee MA, Carbone TA, Badaruddin BS (2007) Revision total hip

218 replacement using cemented collarless double-taper femoral components. J Bone Joint Surg Br 89:879219886

220 13. Sporer SM, Paprosky WG. (2003) Revision total hip arthroplasty: the limits of fully coated stems Clin Orthop Relat Res 417:203-209

14. Weiss RJ, Stark A, Kärrholm J. (2011) A modular cementless stem vs. cemented long-stem prostheses in revision surgery of the hip: a population-based study from the Swedish Hip Arthroplasty Register Acta Orthop 82:136-142

15. Dall D (1986) Exposure of the hip by anterior osteotomy of the greater trochanter. A modified anterolateral approach. J Bone Joint Surg Br 68:382-386

16. Hardinge K (1982) The direct lateral approach to the hip. J Bone Joint Surg Br 64:17-19

17. Lindgren U, Svenson O (1988) A new transtrochanteric approach to the hip. Int Orthop 12:37-41

18. Bolder SB, Verdonschot N, Schreurs BW (2007) Technical factors affecting cup stability in bone impaction grafting. Proc Inst Mech Eng H 221:81-86

19. Haddad FS, Rayan F (2009) The role of impaction grafting: the when and how. Orthopedics 32:675-679

10. Della Valle CJ, Paprosky WG (2004) The femur in revision total hip arthroplasty evaluation and classification. Clin Orthop Relat Res 420:55-62

21. Barrack RL, Mulroy RD Jr, Harris WH (1992) Improved cementing techniques and femoral component loosening in young patients with hip arthroplasty. A 12-year radiographic review. J Bone Joint Surg Br 74:385-389

22. Harris WH, McCarthy JC Jr, O'Neill DA (1982) Femoral component loosening using contemporary techniques of femoral cement fixation. J Bone Joint Surg Am 64:1063-1067

23. Turner RH, Mattingly DA, Scheller A (1987) Femoral revision total hip arthroplasty using a long-stem femoral component. Clinical and radiographic analysis. J Arthroplasty 2:247-258

24. Gie GA, Linder L, Ling RS, Simon JP, Slooff TJ, Timperley AJ (1993) Impacted cancellous allografts and cement for revision total hip arthroplasty. J Bone Joint Surg Br 75:14-21 
245 26. Retpen JB, Jensen JS (1993) Risk factors for recurrent aseptic loosening of the femoral component after 246 cemented revision. J Arthroplasty 8:471-478

247 27. Mann KA, Ayers DC, Damron TA (1997) Effects of stem length on mechanics of the femoral hip 248 component after cemented revision. J Orthop Res 15:62-68

249 28. Sierra RJ, Charity J, Tsiridis E, Timperley JA, Gie GA (2008) The use of long cemented stems for 250 femoral impaction grafting in revision total hip arthroplasty. J Bone Joint Surg Am 90:1330-1336

29. Callaghan JJ, Salvati EA, Pellicci PM, Wilson PD Jr, Ranawat CS (1985) Results of revision for mechanical failure after cemented total hip replacement, 1979 to 1982 . A two to five-year follow-up. J Bone Joint Surg Am 67:1074-1085

30. Strömberg CN, Herberts P (1996) Cemented revision total hip arthroplasties in patients younger than 55 years old. A multicenter evaluation of second-generation cementing technique. J Arthroplasty 11:489499

31. Kavanagh BF, Ilstrup DM, Fitzgerald RH Jr (1985) Revision total hip arthroplasty. J Bone Joint Surg Am 67:517-526

32. Herberts P, Malchau H (1997) How outcome studies have changed total hip arthroplasty practices in Sweden. Clin Orthop Relat Res 344:44-60

33. Dohmae Y, Bechtold JE, Sherman RE, Puno RM, Gustilo RB (1988) Reduction in cement-bone interface shear strength between primary and revision arthroplasty. Clin Orthop Relat Res 236:214-220

34. Pierson JL, Harris WH (1995) Effect of improved cementing techniques on the longevity of fixation in revision cemented femoral arthroplasties. Average 8.8-year follow-up period. J Arthroplasty 10:581-591

35. Mall NA, Nunley RM, Zhu JJ, Maloney WJ, Barrack RL, Clohisy JC (2011) The incidence of acetabular osteolysis in young patients with conventional versus highly crosslinked polyethylene. Clin Orthop Relat 
270 Figure 1. Long stems evaluated in this study are shown. (A) HS-3 long stem, (B) Type 6 long stem, (C) Type 7 271 long stem, and (D) Elite Plus long stem.

272

273 Figure 2. Radiographs of a 66-year-old woman are shown. A definitely loosened Charnley stem (A) was

274 replaced by a Type 6 long stem without bone graft (B). Radiolucent lines confirmed proximally in the initial 275 radiograph progressed distally in 13 years (C, arrows).

276

277 Figure 3. The overall survival rate is $87 \%$ at 15 years with radiological stem failure as the end point. The 278 log-rank test reveals that the quality of the cement mantle significantly affects the failure-free survival (asterisk, $279 \quad \mathrm{p}=0.033)$. 
Click here to download high resolution image

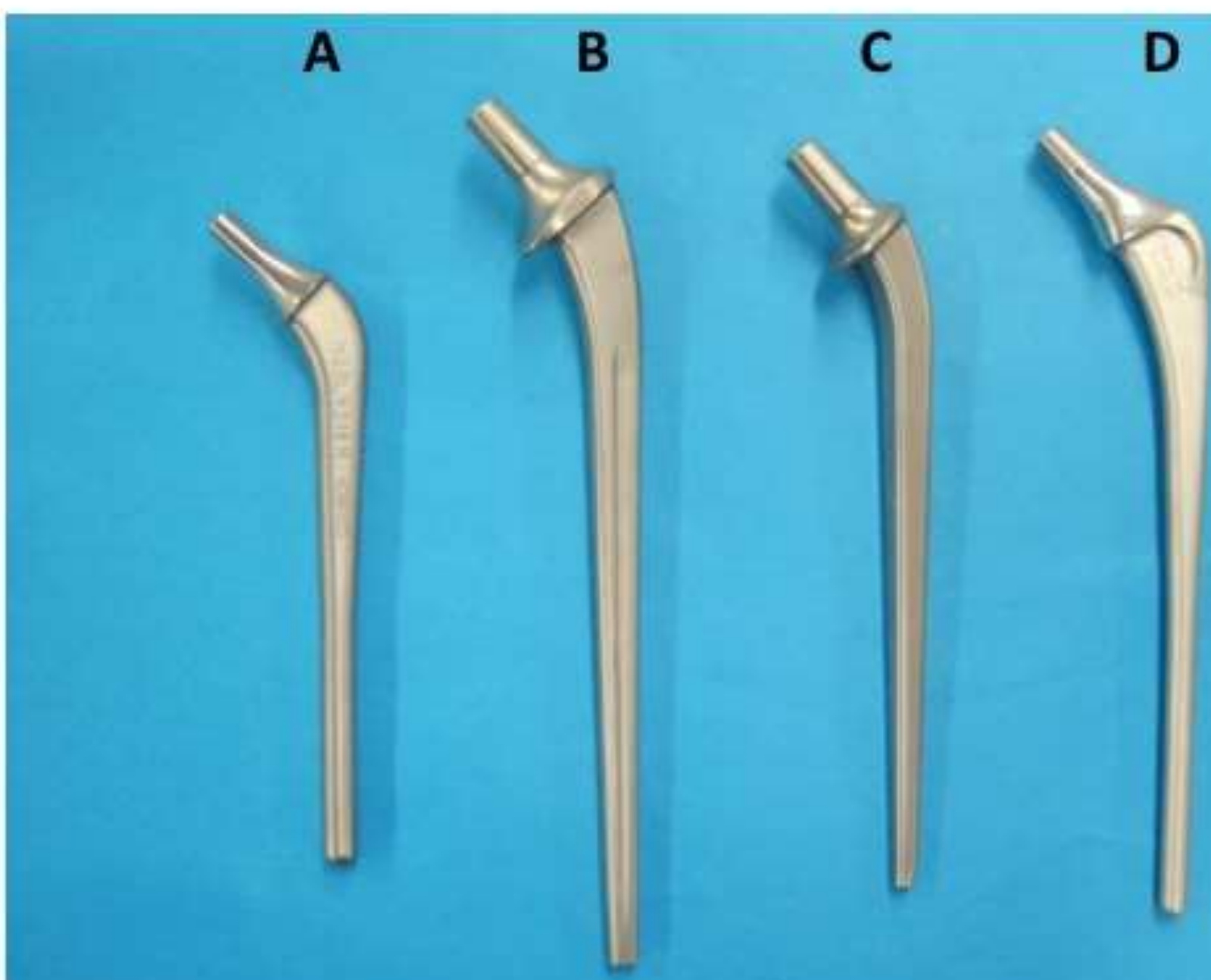

Figure 1 


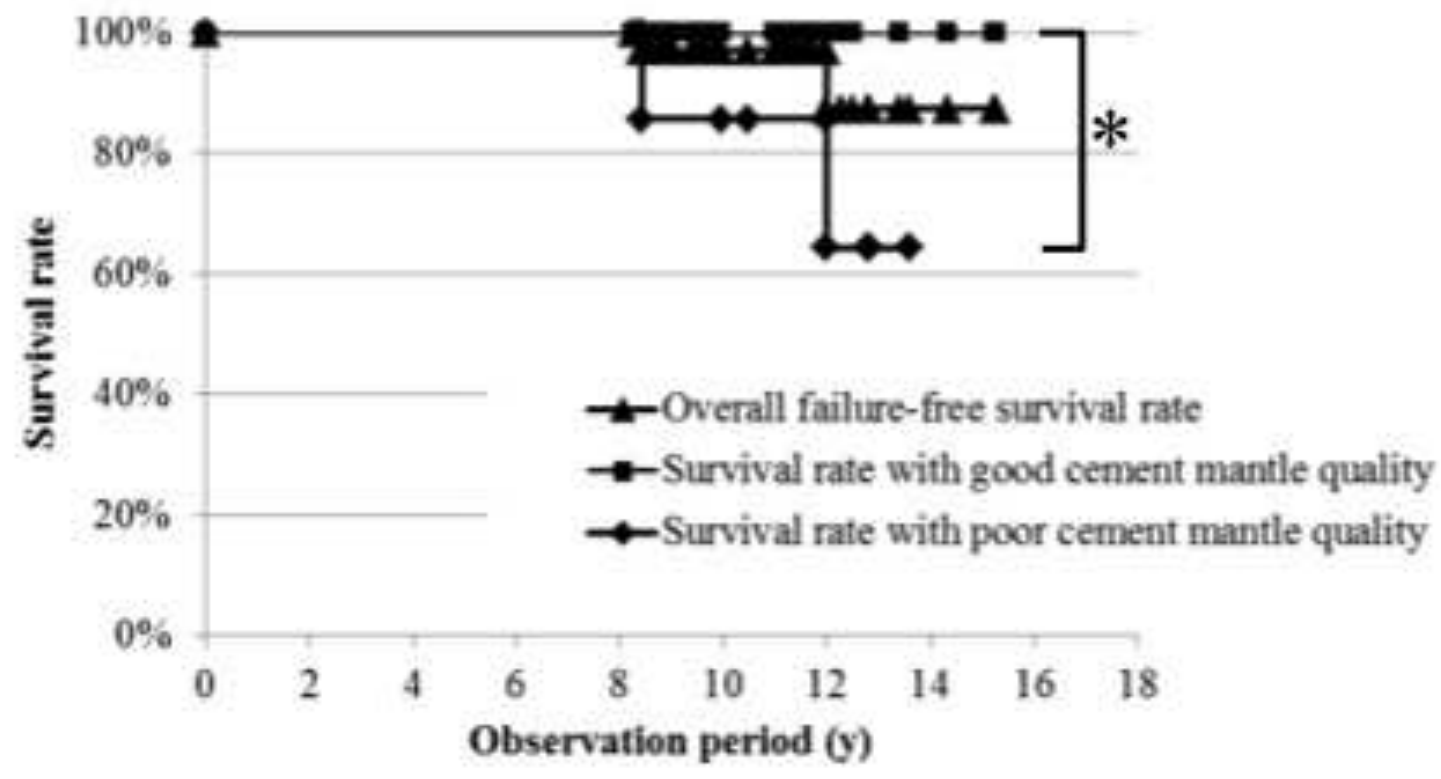

Figure 3 
Table 1. Percentage of cases ( $n=34$ hips in 33 patients) with radiolucent lines occupying $>50 \%$ of each Gruen region on an anteroposterior view

\begin{tabular}{lll}
\hline & Initial \% & Final \% \\
\hline Zone 1 & 35 & 74 \\
Zone 2 & 21 & 24 \\
Zone 3 & 15 & 15 \\
Zone 4 & 0 & 6 \\
Zone 5 & 0 & 12 \\
Zone 6 & 6 & 18 \\
Zone 7 & 35 & 65 \\
\hline
\end{tabular}

